\title{
Manajemen Neuroanestesi pada Operasi Carotid Endarterectomy: Pasien dengan Riwayat Stroke Berulang
}

\author{
Chrismas Gideon Bangun*), RR. Sinta Irina*), Dewi Yulianti Bisri**), Eri Surahman**) \\ ${ }^{* *}$ Departemen Anestesiologi dan Terapi Intensif FK USU-RSUP H. Adam Malik Medan, ${ }^{* *}$ Departemen \\ Anestesiologi dan Terapi Intensif FK UNPAD-RSUP Dr. Hasan Sadikin Bandung
}

\begin{abstract}
Abstrak
Carotid endarterectomy (CEA) adalah prosedur bedah yang dilakukan untuk memulihkan aliran darah karotis dan mengurangi kejadian stroke embolik dan trombotik. Walaupun merupakan prosedur preventif, CEA membawa risiko komplikasi perioperatif: neurologik dan kardiak. Komplikasi mayor CEA adalah stroke intra dan postoperatif, infark miokard, dan kematian. Untuk mengurangi angka kejadian stroke intraoperatif maka dikembangkan teknologi monitoring intraoperatif salah satunya dengan elektroensefalogram (EEG). Pada kasus ini pasien laki-laki, 62 tahun, dengan riwayat stroke iskemik berulang dan kelemahan tungkai kiri direncanakan untuk CEA dengan anestesi umum. Ahli bedah memutuskan untuk menggunakan shunt secara selektif dengan menilai monitoring EEG saat dilakukan clamping. Akhirnya shunt tidak jadi dilakukan, operasi berjalan selama 6 jam, diwarnai dengan gejolak hemodinamik yang sering terjadi pada pasien dengan penyakit karotis akibat gangguan baroreseptor. Dengan penanganan anestesi yang cermat selama dan sesudah operasi, operasi berhasil dilakukan, dan hasil postoperasi kekuatan motorik kaki kiri meningkat dari 2 ke 4.
\end{abstract}

Kata kunci: carotid endarterectomy, monitoring intraoperatif, elektroensefalogram, gejolak hemodinamik, gangguan baroreseptor

JNI 2021; 10 (1): 22-28

\section{Management Neuroanesthesia for Carotid Endarterectomy: Patients with a History of Recurrent Stroke}

\begin{abstract}
Carotid endarterectomy (CEA) is a surgical procedure performed to restore carotid blood flow and reduce the incidence of embolic and thrombotic strokes. Although it is a preventive procedure, CEA carries the risk of perioperative complications: neurologic and cardiac. Major complications of CEA are intra and postoperative stroke, myocardial infarction, and death. To reduce the number of intraoperative stroke events, one of them is to develop intraoperative monitoring technology with electroencephalogram (EEG). In this case, a male patient, 62 years old, with statistics of recurrent stroke and left leg weakness was approved for CEA under general anesthesia. Surgeons decide to use shunt selectively by assessing EEG monitoring when clamping. Finally the shunt was not performed, the operation lasted for 6 hours, tinged with hemodynamic shocks that often occur in patients with carotid disease due to baroreceptor disorders. By managing anesthesia meticulously during and after surgery, the operation was successfully performed, and the results of the post on the left leg strengthening motor increased from 2 to 4 .
\end{abstract}

Key words: carotid endarterectomy, intraoperative monitoring, electroencephalogram, hemodynamic turmoil, baroreceptor disruption.

JNI 2021; 10 (1): 22-28

This article is licensed under a

Creative Commons Attribution-NonCommercial-ShareAlike 4.0 International License.

CChrismas Gideon B, RR. Sinta Irina, Dewi Yulianti B, Eri Surahman

(2021) under the CC-BY-NC-SA license 


\section{Pendahuluan}

Carotid endarterectomy (CEA) adalah operasi preventif yang bertujuan untuk menurunkan risiko kematian atau kecacatan akibat stroke pada pasien dengan stenosis karotis yang signifikan, dimana manfaat dari operasi ini akan didapatkan bila morbiditas dan mortalitas perioperatif nya rendah. Selain stroke perioperatif, pasien yang menjalani CEA juga meningkatkan risikonya bila mempunyai penyakit jantung koroner sebelumnya, hipertensi dan diabetes mellitus. Tekanan darah sering sulit dikendalikan pada pasien yang akan menjalani CEA, padahal kestabilan hemodinamik secara langsung maupun tidak langsung sangat mempengaruhi morbiditas dan mortalitas. Pembedahan karotis sendiri merupakan hal yang khusus, karena salah satu komponen utama dalam mekanisme kontrol fisiologis tekanan arteri, yaitu baroreseptor dalam sinus karotid, mengalami perubahan akibat proses penyakitnya sendiri, dan mungkin terpengaruh oleh manipulasi saat prosedur pembedahan, serta oleh anestesi. Pasien yang menderita transient ischemic attack (TIA) atau stroke baru memiliki sensitivitas baroreseptor yang berubah/ tidak-sesuai, dan karena itu berisiko lebih besar terjadinya ketidakstabilan hemodinamik. ${ }^{1}$

Pembedahan arteri karotis berhubungan dengan disfungsi baroreseptor. Pembedahan pelepasan plak karotid menyebabkan disrupsi parsial segera dari aktivitas baroreseptor yang menyebabkan instabilitas tekanan darah arteri, hal ini mungkin akibat hilangnya sebagian ujung saraf dari lumen arteri. ${ }^{2}$ Hal ini dapat berlangsung beberapa jam hingga beberapa hari setelah pembedahan. Sebagai kaidah umum, kebanyakan anestesiolog dan ahli bedah mentargetkan tekanan sistolik $160 \mathrm{mmHg}$ atau kurang sebelum CEA elektif, melanjutkan terapi sampai pagi hari pembedahan, kecuali ACE inhibitor dan antagonis reseptor angiotensin II, dan terapi dimulai kembali sesegera mungkin setelah pembedahan. Namun penting untuk menekankan bahwa terapi harus disesuaikan secara individu dan penurunan cepat tekanan darah arteri harus dihindari, terutama pada pasien dengan gejala neurologis akut yang baru terjadi. ${ }^{3}$
Berbagai metode telah digunakan untuk memonitor perfusi otak selama pembedahan, menentukan apakah shunting arteri diperlukan (shunting selektif). Metode ini bervariasi dalam biaya dan efektifitas, namun dalam literatur masih diperdebatkan akan keefektivitasnya, yaitu monitoring elektrofisiologis. Monitoring elektrofisiologis yang paling sering untuk CEA adalah elektroensefalogram (EEG), namun somatosensory evoked potentials (SSEP) juga terkadang digunakan bersamaan dengan EEG. ${ }^{4}$

\section{Kasus}

\section{Anamnesa}

Pasien laki-laki, 62 tahun, BB $62 \mathrm{~kg}$, TB $170 \mathrm{~cm}$, dengan riwayat episode multipel stroke iskemik, terakhir 1 bulan yang lalu. Keluhan saat ini kelemahan pada kaki kiri. Riwayat penyakit lain yaitu hipertensi dan dislipidemia. Riwayat diabetes melitus tidak dijumpai. Pasien adalah perokok dengan 3-4 batang sehari selama 50 tahun. Pengobatan saat ini pasien mendapat madiplot, enalapril, atorvastatin, aspirin, clopidogrel (sudah dihentikan sejak 9 hari yang lalu).

\section{Pemeriksaan Fisik}

Penilaian jalan nafas bebas, suara paru vesikuler kiri dan kanan, laju nafas 14 kali permenit. Tekanan darah 120/64 mmHg, laju nadi 80 kali per menit, reguler. Kesadaran composmentis.

\section{Pemeriksaan Neurologi}

Terdapat kelemahan pada kaki kiri dengan skor motorik 2. Tidak ditemukan defisit neurologis lain.

\section{Pemeriksaan Laboratorium dan Radiologis}

Hemoglobin $14 \mathrm{~g} / \mathrm{dL}$, Hematokrit 41,6\%, Leukosit $10.500 / \mathrm{mm}^{3}$, Trombosit $402.000 / \mathrm{mm}^{3}$, Ureum $14 \mathrm{mg} / \mathrm{dL}$, Creatinin $1,03 \mathrm{mg} / \mathrm{dL}, \mathrm{PT} /$ aPTT 12,3 $(12,4) / 45,5(30,7)$ detik, SGOT/SGPT 10/8 U/L, Albumin 4,14 g/dL, Gula Darah Puasa 104 mg/dL, Na/K/Cl 143/3,83/99,7 mEq/L. Pada foto thorax dijumpai elongasi aorta ringan dengan sedikit kalsifikasi menetap paru kanan-kiri. Pada pemeriksaan elektrokardiogram didapatkan normal sinus ritme dengan sesekali premature 


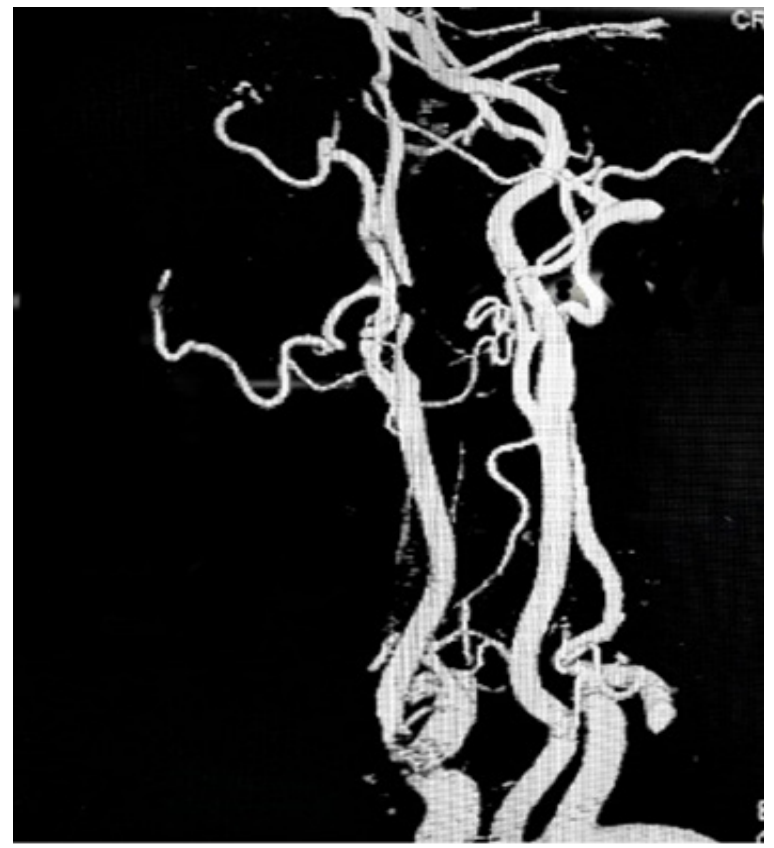

Gambar 1. MRA Preoperatif. Ditemukan penyempitan $98 \%$ bulbus carotid kanan dan penyempitan berat pada segmen $P 1$ distal arteri serebral posterior (PCA) kiri

ventricular complex. Pada pemeriksaan magnetic resonance angiogram ditemukan penyempitan $98 \%$ bulbus carotid kanan dan penyempitan berat pada segmen P1 distal arteri serebral posterior (PCA) kiri. Pada pemeriksaan computed tomography angiography ditemukan perubahan ensefalomalasik pada daerah frontal kanan dan parietal kanan dan infark lakunar lama pada corona radiata kiri.

\section{Persiapan Anestesi}

Pasien digolongkan status ASA 3 dengan riwayat stroke baru, hipertensi, perokok. Direncanakan operasi carotid endarterectomy dengan anestesi umum, dengan monitoring elektroensefalogram (EEG). Ahli bedah menyatakan bahwa penggunaan shunt dipersiapkan namun keputusan apakah shunt dipasang atau tidak dengan melihat kondisi dalam operasi.

\section{Pengelolaan Anestesi}

Pasien dilakukan pemasangan monitor EKG, tekanan darah noninvasif dan saturasi oksigen perifer. Tekanan darah 156/92 $\mathrm{mmHg}$, laju nadi 66 kali permenit, $\mathrm{SpO}_{2}$ 98\%. Dilakukan

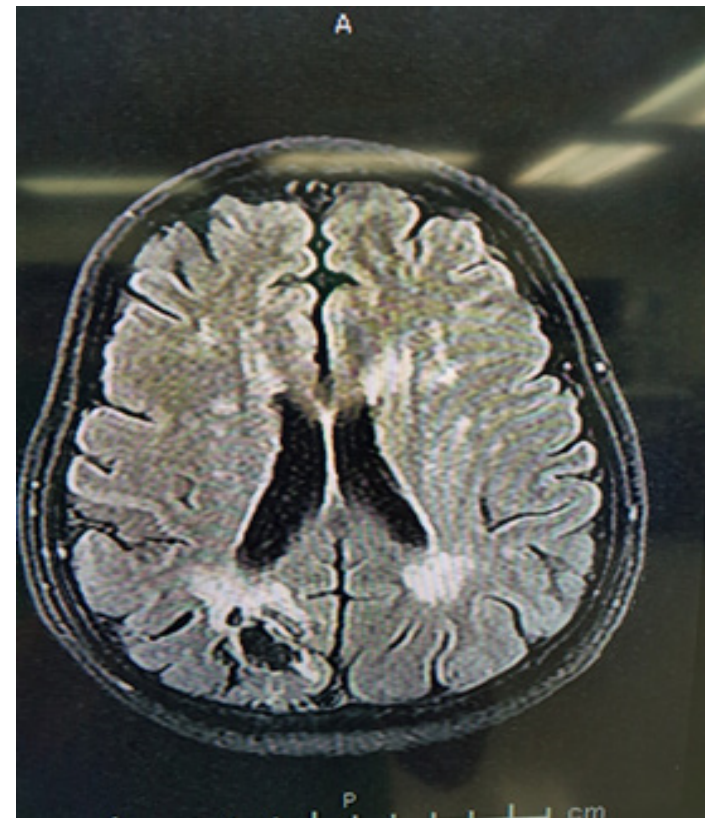

Gambar 2. CTA preoperatif. Ditemukan perubahan ensefalomalasik pada daerah frontal kanan dan parietal kanan dan infark lakunar lama pada corona radiata kiri

oksigenasi, kemudian diberikan fentanyl 100mcg intravena. Induksi dengan propofol $100 \mathrm{mg}$, pelumpuh otot dengan cisatracurium $10 \mathrm{mg}$, kemudian pasien diintubasi dengan ETT no. 7,5 cuff. Kemudian dilakukan pemasangan arteri line. Juga dilakukan pemasangan elektroda EEG. Setelah selesai pemasangan arteri line, tekanan darah naik menjadi 194/104 mmHg, laju nadi 88 kali permenit, diberikan nicardipine $0,4 \mathrm{mg}$ intravena. Rumatan anestesi dengan desflurane 4-6\%, fentanyl ditambahkan $25-50 \mathrm{mcg}$ sesuai hemodinamik, cisatracurium diberikan kontinyu $0,1 \mathrm{mg} / \mathrm{kg} / \mathrm{jam}$. Pasien kemudian diposisikan untuk operasi. Pada 3 jam setelah insisi ahli bedah memberitahu akan dilakukan clamping, diberikan tiophentone $300 \mathrm{mg}$ intravena, waktu clamping ditandai. Selama clamping tekanan darah sistolik tetap dijaga diatas $140 \mathrm{mmHg}$, dipertahankan dengan pemberian efedrin bolus $3 \mathrm{mg}$. Keseluruhan operasi berlangsung selama 6 jam, operasi berlangsung baik, total cairan masuk ringer asetat $600 \mathrm{ml}$, normal saline $900 \mathrm{ml}$, jumlah urin output $520 \mathrm{ml}$ dan perdarahan 100 ml. Selama operasi pemantauan EEG terus dilakukan, dan tidak ditemukan penurunan yang 
Tabel 1. Urutan Kejadian selama Anestesi

\begin{tabular}{|c|c|}
\hline Jam & Kejadian \\
\hline 13.08 & Pasien masuk kamar operasi \\
\hline 13.10 & Pasien diberikan Fentanyl 100mcg \\
\hline 13.15 & $\begin{array}{l}\text { Induksi dengan Propofol 60mg, } \\
\text { cisatracurium } 10 \mathrm{mg}\end{array}$ \\
\hline 13.20 & Intubasi \\
\hline 13.25 & $\begin{array}{l}\text { Hipertensi terdeteksi: TD } \\
\text { 194/104mmHg, HR } 88 \text { kali } \\
\text { permenit, Nicardipine 0,4mg IV } \\
\text { diberikan }\end{array}$ \\
\hline 13.30 & Pemosisian pasien \\
\hline 13.43 & Fentanyl 50mcg \\
\hline 14.03 & Insisi bedah \\
\hline 14.44 & $\begin{array}{l}\text { TD 106/65 mmHg HR } 54 \text { kali per- } \\
\text { menit, diberikan Efedrin } 3 \text { mg IV }\end{array}$ \\
\hline 15.20 & Fentanyl 50mcg \\
\hline 16.40 & Fentanyl 50mcg \\
\hline 16.45 & $\begin{array}{l}\text { TD } 150 / 110 \text { mmHg HR } 71 \text { kali per- } \\
\text { menit, Nicardipine } 0,2+0,4 \mathrm{mg} \text { IV }\end{array}$ \\
\hline 17.05 & $\begin{array}{l}\text { TD } 160 / 100 \mathrm{mmHg} \text {, Nicardipine } \\
0,4 \mathrm{mg} \text { IV }\end{array}$ \\
\hline 17.03 & $\begin{array}{l}\text { Sebelum clamping diberikan Tio- } \\
\text { phental 300mg }\end{array}$ \\
\hline 17.05 & Clamping ICA 17.05-18.15 \\
\hline \multicolumn{2}{|c|}{$\begin{array}{l}\text { Rencana: TD sistolik }>140 \mathrm{mmHg} \text {, Efedrin } 3 \mathrm{mg} \text { IV } \\
\text { diberikan }\end{array}$} \\
\hline 17.31 & $\begin{array}{l}\text { TD 125/70 mmHg, Efedrin } 6 \mathrm{mg} \text { IV } \\
\text { diberikan }\end{array}$ \\
\hline 18.14 & $\begin{array}{l}\text { TD } 167 / 119 \text { mmHg HR } 85 \text { kali per } \\
\text { menit, Nicardipine } 0,2 \text { mg IV }\end{array}$ \\
\hline 18.24 & $\begin{array}{l}\text { TD 161/110 mmHg HR } 88 \text { kali per- } \\
\text { menit, Nicardipine } 0,4+0,4 \mathrm{mg} \text { IV }\end{array}$ \\
\hline 18.30 & Fentanyl $25 \mathrm{mcg}$ \\
\hline 19.22 & Bedah selesai \\
\hline 19.31 & Ekstubasi \\
\hline 19.40 & Pasien pindah ke ICU pascabedah \\
\hline
\end{tabular}

bermakna. Pasien diekstubasi di kamar operasi setelah reversal dengan glycopyrolate $0,4 \mathrm{mg}$ dan prostigmine $2,5 \mathrm{mg}$.

\section{Pascabedah}

Saat 1 jam setelah di pascabedah tekanan darah meningkat menjadi $195 / 110 \mathrm{mmHg}$, laju nadi 100 kali permenit, diberikan labetalol 40mg

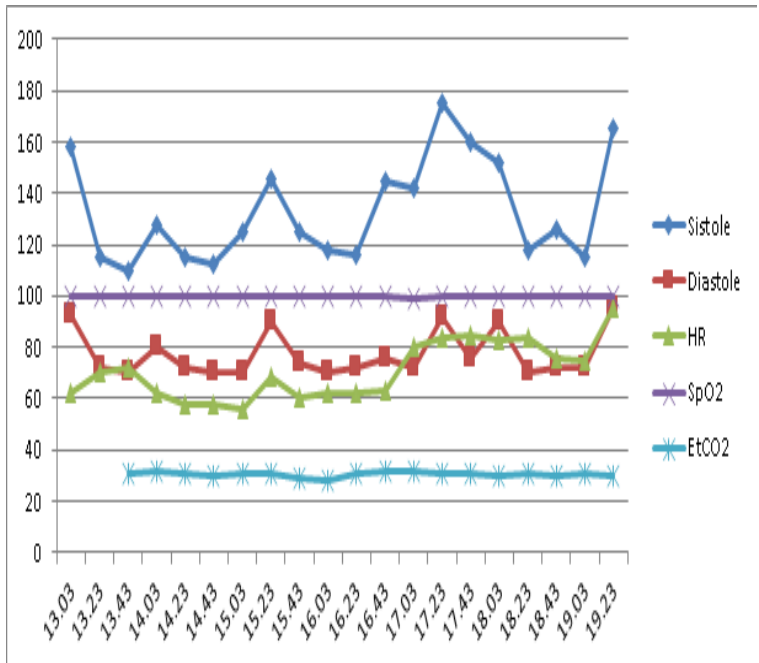

Grafik 1. Monitoring Intraoperatif

intravena, 3 menit kemudian tekanan darah turun menjadi $152 / 76 \mathrm{mmHg}$, laju nadi 80 kali permenit. Analgetik diberikan parasetamol 1g/8 jam dan tramadol $100 \mathrm{mg} / 8 \mathrm{jam}$. Terapi lain diberikan madiplot $10 \mathrm{mg}$, omeprazole $20 \mathrm{mg}$, lorazepam $0,5 \mathrm{mg}$, aspirin $81 \mathrm{mg}$.

\section{Pascabedah hari I}

Keesokan harinya di ruang rawat intensif pascabedah pasien stabil, sadar penuh dengan skala nyeri 1 . Sewaktu dilakukan pemeriksaan neurologis ditemukan kekuatan motorik kaki kiri telah membaik dengan kekuatan motorik 4. Pasien direncanakan untuk pindah ruang rawat pada siang harinya.

\section{Pembahasan}

Pada kasus ini pasien laki-laki, 62 tahun, dengan riwayat episode multipel stroke iskemik, terakhir 1 bulan yang lalu. Keluhan saat ini kelemahan pada kaki kiri. Riwayat penyakit lain yaitu hipertensi dan dislipidemia. Pasien adalah perokok dengan 3-4 batang sehari selama 50 tahun. Merokok dikaitkan dengan penurunan komplians pembuluh darah, penurunan kadar HDL, tingginya agregasi trombosit, penurunan kadar fibrinogen. Sekitar 18\% stroke dikaitkan dengan rokok nikotin. Aterosklerosis terjadi lebih banyak pada baik perokok aktif maupun pasif. Hipertensi adalah faktor risiko utama stroke iskemik yang 
masih dapat dimodifikasi. Kolesterol total dan trigliserida yang tinggi, LDL rendah sangat berkaitan dengan subtipe aterosklerotik dan lakunar pada pasien stroke iskemik. ${ }^{5}$ Ateroma karotid mengurangi tekanan perfusi serebral dan mengganggu refleks baroreseptor dan reaktivitas serebrovaskular, bahkan pada pasien asimtomatik. Reaktivitas barorefleks dan cerebrovaskular yang terganggu adalah prediktor hasil luaran jangka panjang. ${ }^{3}$ Bukti terbaru menekankan tingginya kejadian stroke yang terjadi dalam beberapa hari setelah TIA, sehingga operasi urgensi sekarang disarankan. Walaupun ahli bedah mendukung dilakukannya CEA dini setelah TIA, hal ini dapat membuat penanganan kardiovaskular perioperatif lebih sulit, karena fungsi barorefleks terganggu dalam beberapa minggu setelah TIA ataupun stroke. ${ }^{1}$

Tabel 2. Faktor Risiko Ketidakstabilan Hemodinamik pada Pasien yang menjalani CEA

\begin{tabular}{l} 
Preoperatif \\
Interval yang pendek antara kejadian meurologis \\
simtomatik dan jadwal pembedahan \\
Ateroma karotis bilateral \\
CEA kontralateral sebelumnya atau pembedahan \\
radical neck \\
Hipertensi preoperatif yang kurang terkontrol \\
Intraoperatif \\
Endarterectomy eversi \\
Anestesi lokal pada blok/seksi saraf sinus karotid \\
\hline Dikutip dari: Robinson TG, dkk. Stroke 1997; 28: 1671-6
\end{tabular}

Hipertensi postoperatif sering terjadi setelah CEA. Biasanya bersifat sementara dan memuncak dalam beberapa jam pertama setelah pembedahan, dan biasanya berkaitan dengan fungsi baroreseptor yang terganggu. Hal ini dapat menyebabkan hematoma pada luka, iskemi miokard dan dalam beberapa kasus dapat menyebabkan hiperperfusi serebral. Insidens hipertensi postoperatif berat mencapai $66 \%{ }^{3}$ Hipotensi intraoperatif dan hipertensi postoperatif membuat pasien riskan terjadinya hematom pada luka. CEA sering menyebabkan penyempitan jalan nafas akibat edema, dan hematom pada luka dapat meyebabkan obstruksi akibat kombinasi adanya kompresi dan edema. Dalam beberapa kasus, eksplorasi luka emergensi diperlukan yang memiliki risiko tersendiri. ${ }^{3}$ Target tekanan darah adalah sistolik kurang dari $160 \mathrm{mmHg}$ atau dalam $20 \%$ rentang nilai perioperatif biasa dilakukan, namun lebih baik memilih batas yang lebih rendah pada yang lebih berisiko terhadap hiperperfusi serebral atau hematom luka. ${ }^{3}$ Walaupun telah sering digunakan, vasodilator kerja langsung (seperti sodium nitroprusside, glyceryl trinitrate, nicardipine, dan hydralazine) secara teoritis kurang menguntungkan setelah CEA karena menyebabkan vasodilatasi serebral. Hal ini dapat berbahaya pada pasien yang baru saja mengalami peningkatan aliran darah otak dan autoregulasi yang terganggu setelah CEA. Nifedipine juga menyebabkan vasodilatasi serebral dan bila diberikan sublingual dapat menyebabkan penurunan tekanan arteri yang cepat, sehingga tidak direkomendasikan. Antagonis alfa dan beta adrenergik efektif sebagai pencegahan dan pengobatan hipertensi postoperatif. Sediaan yang ada seperti labetalol, esmolol, metoprolol, atenolol atau klonidin. Labetalol dan esmolol diketahui efektif pada pasien bedah saraf dan keduanya dapat dititrasi pemberiannya sampai tercapai efek yang diinginkan. Antagonis beta adrenergik bermanfaat untuk melawan refleks takikardi dibanding obat-obatan lain. Agonis alfa-2 adrenergik seperti klonidin, bisa diberikan sebelum atau sewaktu pembedahan, mengurangi iskemi miokard, tekanan arteri, dan konsentrasi katekolamin plasma, namun belum ada data yang cukup mengenai penggunaan klonidin pada CEA. ${ }^{3}$

Sewaktu cross-clamping, mempertahankan tekanan darah mendekati 20\% lebih tinggi memiliki efek proteksi dalam hal preservasi perfusi serebral. ${ }^{6}$ Sehingga iskemia fokal dapat dihindari dengan menjamin perfusi serebral. Barbiturat dapatmelindungijaringan otak terhadapterjadinya iskemi fokal. ${ }^{7}$ Dosis tunggal thiopentone menyebabkan supresi tingkat metabolik serebral selama 10 menit dan pemberian kontinyu $3-5 \mathrm{mg} / \mathrm{kg} / \mathrm{jam}$ menunjukkan neuroproteksi. ${ }^{9}$ Ketidakstabilan hemodinamik intraoperatif seperti bradikardia dan hipotensi juga sering dijumpai. Refleks bradikardia dapat ditangani 
dengan atropine, atau lignokain diinfiltrasi lokal pada arteri. ${ }^{8}$ Manajemen temperatur juga dapat dilakukan karena tingkat metabolik serebral turun $7 \%$ untuk setiap penurunan suhu 1 derajat Celcius. Hiperventilasi harus dihindari karena menyebabkan vasokonstriksi pembuluh darah otak, sehingga mengurangi hantaran oksigen. ${ }^{8}$ Setelah ekspos pembedahan secara hati-hati, arteri-arteri karotis komunis, eksterna dan interna di cross-clamping sehingga bifurkasio karotis terisolasi dari sirkulasi. Arteri kemudian dibuka dan plak dilepaskan. Yang sering dilakukan adalah insisi longitudinal, dan arteri diberikan patch saat ditutup untuk mengurangi kejadian re-stenosis. Operasi eversi CEA dimana arteri karotis interna dipotong kemudian dibalikkan sisi luar menjadi sisi dalam. Yang harus diperhatikan adalah melepaskan seluruh debris dari permukaan intima arteri untuk mencegah emboli postoperatif. ${ }^{10}$ Shunt terutama bermanfaat untuk mempertahankan aliran darah serebral pada pasien yang mempunyai stenosis karotid kontralateral atau pada kondisi Circle of Willis yang kurang baik. Komplikasi akut dari insersi shunt adalah emboli udara atau plak, robekan intima, dan diseksi karotid.

Risiko lain setelah pemasangan termasuk hematom, cedera saraf, infeksi, dan restenosis karotid lanjut. Disamping itu ada juga kemungkinan dimana aliran melalui shunt tidak adekuat mencapai kebutuhan oksigen serebral. ${ }^{10}$ Praktek yang dilakukan bervariasi diantara ahli bedah, ada beberapa yang dengan rutin memakai shunt pada semua pasien, sementara ada yang tidak mau menggunakan sama sekali, namun ada juga yang memakai kebijakan selektif, dimana didasarkan pada satu atau lebih monitoring fungsi serebral atau aliran darah serebral. Teknologiuntuk monitoring ini mencakup elektroensefalogram (EEG) dan/atau somatosensory evoked potentials (SSEP). ${ }^{10}$

\section{Monitoring Intraoperatif}

Sewaktu periode cross-clamping, perubahan tekanan darah arterial dapat menyebabkan iskemi serebral. Tekanan darah sistemik harus dinaikkan untuk menjamin aliran melalui sirkulasi kolateral. Rute utama dari sirkulasi kolateral ini adalah jalur Willisi (arteri komunikans anterior, arteri komunikans posterior dan arteri oftalmika melalui arteri karotis eksterna). EEG merekam aktivitas elektrik spontan pada sel-sel kortikal, area yang lebih rentan terhadap menurunnya perfusi. EEG merupakan parameter yang sensitif untuk iskemia karena aktivitas elektrofisiologik memakai 60\% kebutuhan metabolik serebral. Perubahan EEG lebih dari 10 menit berkorelasi kuat dengan defisit neurologis postoperatif, karenanya perubahan EEG yang lebih besar dari derajat ringan adalah indikasi untuk pemakaian shunt atau menginduksi hipertensi. Aliran darah serebral regional adalah $50-55 \mathrm{ml} / \mathrm{menit} / 100 \mathrm{~g}$ jaringan otak. Iskemia biasanya terjadi pada aliran darah $18-20 \mathrm{ml} / \mathrm{menit} / 100 \mathrm{~g}$ jaringan otak dan kematian jaringan pada $8-10 \mathrm{ml} / \mathrm{menit} / 100 \mathrm{~g}$ jaringan otak, yang bermanifestasi sebagai melambatnya frekuensi atau menghilangnya amplitudo, pada iskemi berat bisa terlihat isoelektrik. EEG dipengaruhi oleh iskemi serebral namun teknik ini juga memiliki keterbatasan. Sinyal EEG hanya merefleksikan kejadian kortikal dan tidak menggambarkan iskemi pada struktur yang lebih dalam. Data mentah EEG sulit diinterpretasi, dan monitoring nya secara real time membutuhkan keahlian dan pengalaman khusus. Processed EEG, seperti compressed spectral array, lebih mudah diinterpretasikan namun sebagian informasi penting juga bisa hilang sewaktu konversi ke format compressed. ${ }^{10}$ Secara teoritis SSEP lebih menguntungkan dibanding EEG untuk monitoring iskemi serebral. Monitoring ini menilai tidak hanya korteks namun struktur yang lebih dalam dari otak. Stimulasi dari saraf perifer melewati neuron tingkat pertama dan kedua dan sinaps batang otak sebelum menimbulkan respon di korteks somatosensorik. SSEP memang dapat menunjukkan adanya iskemi serebral, namun tidak lebih spesifik atau sensitif dibanding EEG. Namun SSEP dapat lebih superior pada pasien yang baseline EEG nya sulit diinterpretasi karena stroke sebelumnya. Juga harus diingat bahwa anestesi volatil dapat mengurangi amplitudo SSEP. ${ }^{10}$

\section{Simpulan}

CEA merupakan operasi preventif untuk 
mengurangi risiko kecacatan dan kematian akibat stroke pada pasien dengan stenosis karotis yang signifikan, namun keuntungannya baru akan dirasakan bila morbiditas dan morbilitas perioperatifnya bisa dikendalikan. Ahli bedah mendukung CEA dilakukan dini setelah stroke baru, namun hal ini membuat penanganan kardiovaskular perioperatif lebih sulit, karena fungsi barorefleks terganggu sampai beberapa minggu setelah stroke. Penanganan perlu sangat cermat untuk menjaga tekanan perfusi otak tetap terjaga. Monitoring perfusi serebral sangat diperlukan untuk mendeteksi adanya episode iskemik pada otak. EEG dapat digunakan sebagai metode monitoring yang real time, sehingga setiap deteksi adanya tanda iskemi serebral dapat langsung ditangani. Pemantauan yang cermat sangat diperlukan untuk menjamin keberhasilan tindakan operasi ini.

\section{Daftar Pustaka}

1. Robinson TG, James M, Youde J, Panerai R, Potter J. Cardiac baroreceptor sensitivity is impaired after acute stroke. Stroke 1997; 28: 1671-6.

2. Sigaudo-Roussel D, Evans DH, Naylor AR. Deterioration in carotid baroreflex during carotid endarterectomy. J Vasc Surg 2002; 36: 793-8.

3. Stoneham MD, Thompson JP.Arterial pressure management dan carotid endarterectomy. $\mathrm{Br}$ J Anaesth 2009;102(4):442-52.
4. Liu H, Di Giorgio A, Williams ES, Evans W, Russel MJ. Protocol for electrophysiological monitoring of carotid endarterectomies. Journal of Biomedical Research 2010;24(6):460-6

5. Chong JY, Sacco RL. Risk factors for stroke, assessing risk, and the mass and high-risk approaches for stroke prevention. Continuum Lifelong Learn Neurol. 2005;11:18-34.

6. Allian R, Marone LK, Meltzer J, Jeyabalam G. Carotid endarterectomy. Int Anesthesiology Clin 2005;43:15-38.

7. McConkey A, Kien ND. Cerebral protection with thiopentone during combined carotid endarterectomy and clipping of intraluminal aneurysm. Anesthesia Intensive Care 2007;30:219-22.

8. Karigar SL, Kunakeri S, Shetti AN. Anesthetic management of carotid body tumorexcision: a case report and brief review. Anesth Essays Res 2014;8:259-62.

9. Jagtap SP, Bakhshi RG, Khatavkar SS, Phadtare SJ, Mohite SN. Carotid body tumour excision: anaesthetic challenge and review of literature. Indian J Anaesth 2013;57:76-8.

10. Howell SJ. Carotid endarterectomy. $\mathrm{Br} \mathrm{J}$ Anaesth 2007;99(1):19-31. 